\title{
Morphological analysis by child readers as revealed by the fragment completion task
}

\author{
LAURIE B. FELDMAN \\ State University of New York, Albany, New York \\ and Haskins Laboratories, New Haven, Connecticut \\ JAY RUECKL \\ University of Connecticut, Storrs, Connecticut \\ and Haskins Laboratories, New Haven, Connecticut \\ KRISTEN DILIBERTO \\ Berry College, Mount Berry, Georgia \\ MATTHEW PASTIZZO \\ State University of New York, Albany, New York \\ and Haskins Laboratories, New Haven, Connecticut \\ and \\ FRANK R. VELLUTINO \\ State University of New York, Albany, New York
}

\begin{abstract}
Ten-year-old children performed a fragment completion task. Target fragments (e.g., T__NN) were preceded by four types of study conditions. The identity condition consisted of the target (TURN). The morphological condition included a related form (TURNED). The orthographic condition consisted of morphologically unrelated words (e.g., TURNIP). Finally, no similar word was presented in the study phase of the no-prime condition. Morphological relatives included orthographically transparent (TURNEDTURN) and orthographically opaque (RIDDEN-RIDE) forms. The results indicated that performance of child readers on the fragment completion task was sensitive to morphological relationships. Completion rates following opaque, as well as transparent, morphological relatives were significantly greater than those following orthographically similar forms. In sum, the fragment completion task provides a viable new tool for examining morphological processing in children and for differentiating morphological effects from effects of similar form.
\end{abstract}

Many believe that knowledge of a word's phonological characteristics is the single most important factor in a child's learning to read (e.g., Bryant \& Bradley, 1985; Liberman, Shankweiler, \& Liberman, 1989; Tunmer, 1988). To provide a window on their phonological development, children are sometimes asked to categorize words on the basis of phonological segments (Bradley \& Bryant, 1983 ) or to count phonological segments (Fox \& Routh, 1976; Yopp, 1988). Knowledge about a word's morpho-

The research reported here was supported by funds from National Institute of Child Health and Development Grant HD-01994 to Haskins Laboratories. We thank the teachers and principals of the Niskayuna elementary schools for their cooperation and Brenda Coehlo and Kevin Haggerty for collecting the data. Correspondence concerning this article should be sent to L. B. Feldman or J. Rueckl, Haskins Laboratories, 270 Crown Street, New Haven, CT 06511 (e-mail: 1f503@albany.edu) or to F. R. Vellutino, the Child Research and Study Center, Husted 134, SUNY Albany, Albany, NY 12222. logical structure is also a factor in learning to read. To provide a window on morphological development, children can be asked to decide whether one larger word "contains" another smaller word (e.g., Rubin, 1988) or to produce a morphologically complex form from a simple form that is either a real word (e.g., Carlisle, 1988) or a nonsense word (e.g., Berko, 1958; Britain, 1970; Elbro, 1989). Poor readers have more trouble producing morphologically appropriate completions to a sentence than do better readers (Carlisle, 1987, 1995). Moreover, the differences between good and poor readers are even larger for morphologically complex derivations that undergo orthographic and phonological changes to the base morpheme, such as DECIDEDECISION, relative to those that do not, such as AGREEAGREEABLE (Fowler \& Liberman, 1995). These effects are not limited to poor readers of English. Across a range of reading levels in both Turkish and Serbian, the effect of complexities of sound change in a morphological production task was found to be correlated with performance in a 
phonological task (Fowler, Feldman, Andjelković, \& Oney, in press).

Stated generally, studies of language processing with children have encompassed a great variety of tasks, and the outcomes tend to be interpreted as revealing that children read words analytically with respect to their linguistic components. It should be noted, however, that many of the tasks developed for children require awareness of units-for example, of a word's morphologicalcomponents. Consequently, a concern is that to the extent that morphological performance is less than optimal in these tasks, it may be limited by awareness. In essence, our understanding of morphological processing in children may be constrained by properties of the particular experimental tasks that we employ.

In contrast, many of the tasks that have been used to study morphological processing in adults do not require the explicit manipulation of morphological units (for reviews, see Drews \& Zwitserlood, 1995; Frost, Forster, \& Deutsch, 1997; Marslen-Wilson, Tyler, Waksler, \& Older, 1994; Rueckl, Mikolinski, Raveh, Miner, \& Mars, 1997; Stolz \& Feldman, 1995). One such paradigm involves a variation on the repetition-priming paradigm. Readers perform a task, such as lexical decision or naming, with repetition of some of the target words, at a lag on the order of minutes to hours.

In the morphological variant of the long-term repetitionpriming paradigm, the presentation of a target word (e.g., CAR) is preceded by a morphologically related word (e.g., CARS). The interesting finding is that a morphological relative proves to be an effective prime of the target, improving both the speed and the accuracy with which the target is processed. In contrast, under the same conditions, morphologically unrelated primes that are similar to the target on either orthographic (e.g., CARD) or semantic (e.g., AUTOMOBILE) dimensions have little or no effect on the identification of the target (e.g., Drews \& Zwitserlood, 1995; Feldman, 2000; Feldman \& Moskovljević, 1987; and Bentin \& Feldman, 1990, and Napps, 1989, respectively). Thus, morphological priming is truly morphological in nature, and the ease with which morphological priming effects can be obtained speaks to the important role of morphological structure in word recognition.

To our knowledge, investigations of morphological priming have been conducted only with adult readers. Thus, one goal of the present study was to investigate morphological priming effects in young readers. We used the fragment completion task, in which the participant is shown a word fragment (e.g., $\mathrm{T}_{-} \mathrm{N}_{\mathrm{N}}$ ) and is asked to respond with the first word that comes to mind that forms a legal completion of the fragment. Facilitation is indexed by a change in the probability of producing a given completion (e.g., TURN), relative to an unprimed baseline condition. Morphological facilitation in the fragment completion task has been reported in several recent studies with skilled readers (Raveh \& Rueckl, 2000; Rueckl et al., 1997), and for our purposes, the fragment completion task seemed more appropriate than other common tasks, such as lexical decision. First, we were concerned that the response times of young readers in the lexical decision task would be highly variable, potentially obscuring any effect of the priming manipulation. Moreover, although priming studies involving lexical decision latencies with children can be problematic, priming in the fragment completion task (with identical repetition) has been demonstrated in several studies with children as young as 7 years of age (Komatsu, Naito, \& Fuke, 1996; Naito, 1990).

A second objective of this study concerned the distinction between morphological relatives that are formally (viz., orthographically and phonologically) opaque and those that are transparent (e.g., RIDE-RIDDEN vs. MARKMARKING). Although much is known about the effects of orthographic transparency on skilled reading (see Stolz \& Feldman, 1995, for a review), relatively little is known about the processing of transparent and opaque words by beginning readers. One suggestive finding was reported by Fowler and Liberman (1995), who observed that opaque words were more difficult for children to generate in a sentence completion task. If a child's appreciation of morphological relationships can be diminished by orthographic and phonological changes, as this result suggests, one might expect that formal transparency will influence word perception, as well as word production. Indeed, such an effect would be consistent with certain accounts of skilled reading (e.g., Burani \& Laudanna, 1992; Stanners, Neiser, Hernon, \& Hall, 1979), which hold that transparent and opaque forms tend to be identified in different ways. (According to these theories, transparent words are more likely to be identified by a procedure that parses them into their morphemic constituents, and opaque words are more likely to be identified by reference to whole-word representations. Not coincidentally, these accounts are similar to two-process theories for the production of regular and irregular past tense forms [e.g., Pinker, 1991; Pinker \& Prince, 1988]).

In light of these considerations, the primes in our experiment included both transparent and opaque morphological relatives of the target words. We also included morphologicallyunrelated but orthographically similar primes, thus providing a control condition that could be used to assess whether any priming in the morphological condition was truly morphological in origin. However, the inclusion of both transparent and opaque morphological primes complicates the choice of an appropriate orthographic control condition. Morphologically transparent relatives (e.g., TURNED) tend to preserve the sequence of letters that form the base morpheme (e.g., TURN), whereas opaque relatives (e.g., RIDDEN) fail to preserve the integrity of the base morpheme (e.g., RIDE). Controlling for the orthographic similarity of transparent items entails preserving the complete sequence of letters that forms the base morpheme of the target (e.g., TURNIP). By contrast, the orthographic controls for opaque relatives only partially preserve the sequence of letters that forms the base 
morpheme (e.g., RIDDLE). Thus, the orthographic controls for transparent and opaque relatives differ with respect to the degree of orthographic similarity with their targets.

One way to differentiate the effects of morphological transparency and orthographic similarity is to construct orthographic controls for transparent items that preserve only partial overlap with their targets (as do opaque primes). Thus, in our experiment, we included three stimulus conditions. In the opaque condition, the items included target words, their morphologically opaque primes, and partially overlapping orthographic controls (e.g., RIDE-RIDDEN-RIDDLE). In the transparent.complete (transparent.c) condition, each target word was paired with morphological and orthographic primes that completely overlapped with it (e.g., TURN-TURNED-TURNIP). Finally, in the transparent.partial (transparent.p) condition, target words were paired with a morphologically transparent prime and with an orthographic prime that only partially overlapped with the letters of the target (e.g., MARK-MARKING-MASKING).

\section{METHOD}

\section{Participants}

Eighty-eight fifth-grade students from four public elementary schools in a suburb of Albany participated in the experiment. All were native speakers of English.

\section{Materials}

Three groups of English materials were constructed. Two groups included 20 sets of morphologically transparent forms with orthographically transparent base morphemes (TURNED-TURN). The third consisted of 20 sets of morphologically opaque forms with orthographically opaque base morphemes (RIDDEN-RIDE). As was described above, the items in the transparent.c condition had orthographic study words (TURNIP) that were matched item by item (position sensitive) for orthographic similarity to morphological study words (TURNED). Moreover, the target (TURN) was nested within both the orthographic and the morphological study words. By contrast, neither the orthographic nor the morphological study words for opaque items included the full target. To more closely parallel the structure of the study words for opaque targets, we created a set of transparent.p items. They had orthographic study words (MASKING) whose letters only partially overlapped the target word (MARK) and, consequently, were not matched for positional overlap to the morphological study word (MARKING). Each of the 20 sets within a condition consisted of three study words that were used in the study portion of the task and a fragment for subsequent completion in the fragment completion portion of the task. The identity study item (TURN, RIDE, MARK) consisted of a word that was a potential completion for the fragment. The morphological study item (TURNED, RIDDEN, MARKING) consisted of a word that was related morphologically to the fragment. The orthographic study item (TURNIP, RIDDLE, MASKING) consisted of a word that was related orthographically to the fragment. In addition to the identity, morphological, and orthographic study conditions, the design of the experiment included a baseline condition in which the target word was unrelated to any of the study items.

Across conditions, the study words did not differ in frequency as measured by the Harris and Jacobson (1982) norms. All the study items were real words familiar to third-grade students according to the Harris and Jacobson norms. As is evident from Table 1, frequencies for the transparent.p items more closely matched those for the opaque items than did those for the transparent.c items. Their attributes are summarized in Table 1.
Word fragments were constructed by deleting at least one letter from the item in the identity study condition. Deleted letters were selected so that neither the morphological nor the orthographic study word was a possible completion for the fragment. Generally, the number of letters deleted from each word was two, with the exception of words that contained only three letters. In those cases, only one letter was deleted. In addition, on the basis of the results of pilot testing, the fragments always retained the first letter. For example, following the study words RIDDEN and RIDDLE, the fragment R _ $E$ E was presented. Note that neither RIDDEN nor RIDDLE is a possible completion for the fragment. However, also note that besides the identity study item RIDE, there were several additional items that could have been generated by fifth graders to complete the fragment $\mathrm{R}_{-}$- E. These include such words as RICE, ROPE, RAKE, and RACE. All the fragments permitted at least two completions. Experimental materials are listed in the Appendix.

\section{Design}

Four study orders were created for each set of items. Target fragments in the no-prime condition did not have a corresponding item in the study condition. Therefore, each study order included 15 tokens from three of the four conditions (viz., identity, orthographic, and morphological), and across the four study orders, each fragment was preceded by all four study conditions. The participants were randomly assigned to one of the four study orders.

\section{Procedure}

The children were tested individually. Materials were presented on $5 \times 7$ in. file cards, one word to a card. Words were typed in black lowercase letters in bold 72-point New York style font. The experimenter read through the cards with the child two times. Each card was presented for approximately $1 \mathrm{sec}$, and the order was randomized. At the end of the study phase, each child was given a sheet of paper with 20 fragments and was instructed to find a solution for each one. Before each child began the task, the experimenter went over one example that appeared at the top of the sheet of paper. The children were prompted as they proceeded through the list as follows: "Can you think of a way to make this into a word?" At the end, the experimenter directed the child's attention to each blank fragment and asked once again whether a word came to mind.

Fifth graders viewed transparent.c, transparent.p, and opaque materials in one experimental session. The three sets were counterbalanced for order of presentation, and the session lasted about $20 \mathrm{~min}$.

\section{RESULTS}

The primary analysis focused on the influence of the study phase on target completions. Table 2 summarizes

Table 1

Attributes of Stimulus Materials

\begin{tabular}{llcrc}
\hline & \multicolumn{4}{c}{ Frequency } \\
\cline { 2 - 3 } Study Condition & Material & $M$ & $S D$ & Length in Letters \\
\hline \multicolumn{4}{c}{ Transparent.Complete } \\
Orthographic & turnip & 589 & 912 & 5.8 \\
Morphological & turned & 858 & 1,321 & 5.6 \\
Identity & turn & 929 & 1,300 & 3.8 \\
& \multicolumn{4}{c}{ Opaque } \\
Orthographic & riddle & 600 & \\
Morphological & ridden & 1,473 & 2,167 & 4.1 \\
Identity & ride & 1,743 & 2,342 & 4.3 \\
& \multicolumn{2}{c}{ Transparent.Partial } \\
Orthographic & masking & 1,061 & 1,696 & \\
Morphological & marking & 1,493 & 2,036 \\
Identity & mark & 1,581 & 2,029 \\
\hline
\end{tabular}


Table 2

Percentages of Completion of Target Words by Fifth Graders and Priming for Two Types of Transparent Fragments and Opaque Fragments Preceded in the Study Phase by No Related Form, an Orthographically Related Form, a Morphologically Related Form, and an Identical Form

\begin{tabular}{|c|c|c|c|c|}
\hline Study Condition & Fragment & Prime & Completion $(\%)$ & Priming $(\%)$ \\
\hline \multicolumn{5}{|c|}{ Transparent.Complete } \\
\hline No prime & $\mathrm{T}_{--} \mathrm{N}$ & - & 28 & - \\
\hline Orthographic & $\mathrm{T}_{-}{ }_{-} \mathrm{N}$ & turnip & 46 & 18 \\
\hline Morphological & $\mathrm{T}_{-} \mathrm{N}$ & turned & 58 & 30 \\
\hline Identity & $\mathrm{T}_{--} \mathrm{N}$ & turn & 72 & 44 \\
\hline \multicolumn{5}{|c|}{ Opaque } \\
\hline No prime & $R_{-} \_E$ & - & 37 & - \\
\hline Orthographic & $R_{-} E$ & riddle & 37 & 0 \\
\hline Morphological & $R_{-} E$ & ridden & 53 & 16 \\
\hline Identity & $\mathrm{R}_{-} \mathrm{E}$ & ride & 69 & 32 \\
\hline \multicolumn{5}{|c|}{ Transparent.Partial } \\
\hline No prime & M_R_ & - & 34 & - \\
\hline Orthographic & M_R_ & masking & 38 & 4 \\
\hline Morphological & M_R_- & marking & 69 & 35 \\
\hline Identity & M_R_- & mark & 73 & 39 \\
\hline
\end{tabular}

the target completion rates for morphologically transparent (two types) and opaque fragments in each of the four study conditions for fifth graders. Priming was greatest for fragments that followed identical words in the study condition, intermediate for those that followed morphologically related words, and smallest for those that followed orthographically similar words. For transparent.c types, but not for opaque or transparent.p types, presentation of an orthographically similar word in the study phase also produced significant priming.

This pattern was confirmed by analyses of variance (ANOVAs). The interaction of study condition and morphological transparency (three levels) was significant $\left[F_{1}(6,522)=5.18, M S_{\mathrm{e}}=0.55, p<.0001 ; F_{2}(3,171)=\right.$ $\left.3.45, M S_{\mathrm{e}}=0.0184, p<.005\right]$. Accordingly, we performed separate analyses for the three types of targets.

\section{Morphologically Transparent.C Forms}

Results of an ANOVA indicated that for transparent.c items, the effect of study condition was significant $\left[F_{1}(3,261)=70.79, M S_{\mathrm{e}}=0.043, p<.0001 ; F_{2}(3,57)=\right.$ $\left.33.60, M S_{\mathrm{e}}=0.018, p<.0001\right]$. All pairwise planned comparisons with the no-prime condition were significant both by participants and by items $(p<.005)$. Completion rates for the fragment as the target were highest following prior presentation of the target, intermediate following presentation of a morphological relative of the target, and lowest following an orthographically similar study word. Each of these differences was significant.

\section{Morphologically Opaque Forms}

Results of an ANOVA indicated that the effect of study condition was significant for morphologically opaque forms as well $\left[F_{1}(3,261)=40.82, M S_{\mathrm{e}}=0.05, p<.0001\right.$; $\left.F_{2}(3,57)=31.03, M S_{\mathrm{e}}=0.014, p<.0001\right]$. Pairwise planned comparisons indicated that fragment completion rates following the orthographic study condition did not differ from those following the no-prime condition. All other contrasts with the no-prime condition were significant both by participants and by items $(p<.01)$. Thus, completion rates were significantly higher following prior presentation of the target than following presentation of one of its morphological relatives. Completions in both of these conditions were higher than those in the no-prime condition or in the orthographic condition.

\section{Morphologically Transparent.P Forms}

Results of an ANOVA indicated that for transparent.p items matched on target frequency to opaque items, the effect of study condition was significant $\left[F_{1}(3,261)=\right.$ $59.85, M S_{\mathrm{e}}=0.0461, p<.0001 ; F_{2}(3,57)=39.26, M S_{\mathrm{e}}=$ $0.02, p<.001]$. Pairwise planned comparisons indicated that fragment completion rates following the orthographic study condition did not differ from those following the noprime condition. All other contrasts were significant both by participants and by items $(p<.005)$. Thus, completion rates were significantly higher following prior presentation of the target than following presentation of one of its morphological relatives. Completions in both of these conditions were higher than those in the no-prime condition. Interestingly, and in contrast to the original transparent items, performance after the orthographic study condition for transparent.p items did not differ from that following the no-prime condition.

\section{Comparisons Across Morphological Conditions}

An analysis based on difference scores (related vs. no prime) is informative in evaluating whether the magnitudes of priming were comparable across conditions.

Identity priming did not differ significantly across conditions. Numerical differences suggest that baselines were lower and identity priming was higher for transparent.c items because they were lower in frequency. The construction of transparent.p materials entailed better match- 
ing of frequencies to those of opaque targets. Importantly, when transparent.p items had frequencies that matched those of opaque targets, baseline and identity differences disappeared. However, there was greater morphological facilitation for both types of transparent targets (transparent.c and transparent.p) than for opaque targets $\left[F_{1}(1,348)=\right.$ $14.09, M S_{\mathrm{e}}=0.057, p<.0005 ; F_{2}(1,38)=3.54, M S_{\mathrm{e}}=$ $0.043, p<.07$; and $F_{1}(1,348)=29.29, M S_{\mathrm{e}}=0.057, p<$ $.0001 ; F_{2}(1,38)=10.22, M S_{\mathrm{e}}=0.04, p<.005$, respectively], but priming did not differ between transparent.c and transparent.pitems. Finally, orthographic priming was larger in the transparent.c condition than in the transparent.p and opaque conditions. Thus, even for transparent items, orthographic priming was sensitive to the degree of orthographic overlap.

\section{DISCUSSION}

Morphologicalpriming was evident in the fragment completion task with fifth graders for transparent and opaque relatives, and its magnitude was greater for transparent.c and transparent.p targets than for opaque targets. Generally, target completion rates were highest following identical study words but also increased significantly following presentation of one of its morphological relatives.

This pattern is consistent with that of adults reported by Rueckl et al. (1997) with the same task. The results reveal not only that young readers have knowledge of the morphological structure of the words that they read, but also that they use that knowledge even in tasks in which it is not explicitly required. ${ }^{1}$

Morphological priming occurred with both transparent and opaque forms. Thus, if transparent and opaque primes are identified by different processes and, hence, give rise to morphological priming via different mechanisms, both mechanisms appear to be in place by the early grades. Alternatively, even if these priming effects share a common origin, our results indicate that the morphological organization of fifth graders' lexicon is established well enough to capture relationships that might have been obscured by differences in orthography and phonology.

Although morphological priming was found following transparent as well as following opaque primes, its magnitude was greater in the transparent conditions. Given that orthographic priming was found in the transparent.c condition (with complete overlap of a target and its orthographic prime), but not in the transparent.p condition, the difference in morphological priming from transparent and opaque relatives may well reflect differences in the degree of orthographic similarity, rather than categorical differences in the way that morphologically transparent and opaque words are processed. This interpretation is in line with previous results (Rueckl et al., 1997) demonstrating that morphological priming varies as a function of the degree of orthographic similarity (e.g., MADE-MAKE vs. TOOK-TAKE) within a morphological class (irregular inflections). It also fits with other results demonstrating that morphological effects vary as a function of similarity along orthographic, phonological, and semantic dimensions (Gonnerman, Andersen, \& Seidenberg, 1999; Rueck1 et al., 1997).

Interestingly, the present results suggest that young readers are more sensitive to orthographic overlap than are adults. That is, for morphologically transparent.c forms, the orthographic study condition produced significant facilitation relative to the no-prime condition. In contrast, with similar materials, Rueckl et al. (1997) found only a weak and nonsignificant trend toward facilitation following presentation of orthographically similar but morphologically unrelated primes. It is not unreasonable to suppose that the observed pattern of results provides an initial glimpse into the distillation of morphological structure in the lexicon, and if so, it suggests an important role for orthographic similarity in this developmental process. The contrasting patterns of results with younger and older readers suggest that it may be possible to use priming effects to track the structuring of the lexical system over the course of experience. Further study will reveal the merits of this approach.

\section{REFERENCES}

Bentin, S., \& Feldman, L. B. (1990). The contribution of morphological and semantic relatedness to repetition priming at short and long lags: Evidence from Hebrew. Quarterly Journal of Experimental Psychology, 42A, 693-711.

Berko, J. (1958). The child's learning of English morphology. Word, 14, $150-177$.

Bradley, L., \& Bryant, P. E. (1983). Categorizing sounds and learning to read: A causal connection. Nature, 301, 419-421.

BRITAIN, M. (1970). Inflectional performance and early reading achievement. Reading Research Quarterly, 6, 34-38.

Bryant, P., \& BRADLEy, L. (1985). Children's reading problems. Oxford: Blackwell.

Burani, C., \& Laudanna, A. (1992). Units of representation for derived words in the lexicon. In R. Frost \& L. Katz (Eds.), Orthography, phonology, morphology, and meaning (Advances in psychology, Vol. 94, pp. 27-44). Amsterdam: Elsevier.

CARlisle, J. F. (1987). The use of morphological knowledge in spelling derived forms by learning disabled and normal students. Annals of Dyslexia, 37, 90-108.

Carlisle, J. F. (1988). Knowledge of derivational morphology and spelling ability in fourth, sixth, and eighth graders. Applied Psycholinguistics, 9, 247-266.

CARLISLE, J. F. (1995). Morphological awareness and early reading achievement. In L. B. Feldman (Ed.), Morphological aspects of language processing (pp. 189-209). Hillsdale, NJ: Erlbaum.

Drews, E., \& ZWITSERLOOD, P. (1995). Morphological and orthographic similarity in visual word recognition. Journal of Experimental Psychology: Human Perception \& Performance, 21, 1098-1116.

Elbro, C. (1989). Morphological awareness in dyslexia. In C. von Euler (Ed.), Brain and reading (Wenner-Gren international symposium series, Vol. 54). Basingstoke, U.K.: Macmillan.

Feldman, L. B. (2000). Are morphological effects distinguishable from the effects of shared meaning and shared form? Journal of Experimental Psychology: Learning, Memory, \& Cognition, 26, 1431-1444.

Feldman, L. B., \& Moskovljević, J. (1987). Repetition priming is not purely episodic in origin. Journal of Experimental Psychology: Learning, Memory, \& Cognition, 13, 573-581.

Fowler, A., Feldman. L. B., Andjelković, D., \& Oney, B. (in press). Morphological and phonological analysis by beginning readers: Evidence from Serbo-Croatian and Turkish. In E. Assink \& D. Sandra (Eds.), Reading complex words: Neuropsychology and cognition. Amsterdam: Kluwer. 
Fowler, A., \& Liberman, I. (1995). Morphological awareness as related to early reading and spelling ability. In L. B. Feldman (Ed.), Morphological aspects of language processing (pp. 157-188). Hillsdale, NJ: Erlbaum.

Fox, B., \& Routh, D. K. (1976). Phonemic analysis and synthesis as word attack skills. Journal of Educational Psychology, 68, 70-74.

Frost, R., Forster, K., \& Deutsch, A. (1997). What can we learn from the morphology of Hebrew? A masked priming investigation of morphological representation. Journal of Experimental Psychology: Learning, Memory, \& Cognition, 23, 829-856.

Gonnerman, L. M., Andersen, J. T., \& Seidenberg, M. S. (1999). Graded semantic and phonologicaleffects in priming: Evidence for a distributed connectionist approach. Manuscript submitted for publication.

HARRIS, A. J., \& JACOBSON, M. D. (1982). Basic reading vocabularies. New York: Macmillan.

Komatsu, S. I., Naito, M., \& Fuke, T. (1996). Age-related and intelligence-related differences in implicit memory: Effects of generation on a word-fragment completion test. Journal of Experimental Child Psychology, 62, 151-172.

Liberman, I. Y., Shankweiler, D., \& Liberman, A. M. (1989). The alphabetic principle and learning to read. In D. Shankweiler \& I. Y. Liberman (Eds.), Phonology and reading disability (pp. 1-33). Ann Arbor: University of Michigan Press.

Marslen-Wilson, W., Tyler, L. K., Waksler, R., \& Older, L. (1994). Morphology and meaning in the English lexicon. Psychological Review, 101, 3-33.

NaITo, M. (1990). Repetition priming in children and adults: Age-related dissociation between implicit and explicit memory. Journal of Experimental Child Psychology, 50, 462-484.

NAPPS, S. E. (1989). Morphemic relationships in the lexicon: Are they distinct from semantic and formal relationships? Memory \& Cognition, 17, 729-739.

PINKER, S. (1991). Rules of language. Science, 153, 530-535.

Pinker, S., \& Prince, A. (1988). On language and connectionism: Analysis of a parallel distributed processing model of language acquisition. Cognition, 28, 73-193.
Raveh, M., \& RueckL, J. (2000). Equivalent effects of inflected and derived primes: Long-term morphological priming in fragment completion and lexical decision. Journal of Memory \& Language, 42, $103-$ 119.

Rubin, H. (1988). Morphological knowledge and early writing ability. Language \& Speech, 31, 337-355.

Rueckl, J. G., Mikolinski, M., Raveh, M., Miner, C. S., \& Mars, F. (1997). Morphological priming, connectionist networks, and masked fragment completion. Journal of Memory \& Language, 36, 382-405.

Stanners, R. F., Neiser, J. J., Hernon, W. P., \& Hall, R. (1979). Memory representation for morphologically related words. Journal of Verbal Learning \& Verbal Behavior, 18, 399-412.

Stolz, J. A., \& Feldman, L. B. (1995). The role of orthographic and semantic transparency of the base morpheme in morphological processing. In L. B. Feldman (Ed.), Morphological aspects of language processing (pp. 109-130). Hillsdale, NJ: Erlbaum.

Tunmer, W. (1988). Metalinguistic abilities and beginning reading. Reading Research Quarterly, 23, 134-158.

Yopp, H. K. (1988). The validity and reliability of phonemic awareness tests. Reading Research Quarterly, 23, 159-177.

\section{NOTE}

1. The main point here is that, in contrast to the tasks more typically used to investigate morphological processing in children, in the fragment completion task, participants are not required to explicitly decompose words into their morphological constituents. This is a somewhat different claim from the claim that our participants did not use explicit memory. Although we do not have direct evidence against this possibility, it is worth noting that morphological priming has been dissociated from explicit memory in a fragment completion study with adult participants (Rueckl et al., 1997) and that dissociations between explicit memory and identity priming have been demonstrated with children of approximately the same age as those in our study (Komatsu et al., 1996; Naito, 1990). In light of these findings, it is not unreasonable to conclude that our results were due to implicit (rather than explicit) memory, although this issue is not of primary concern.

\section{APPENDIX}

\begin{tabular}{|c|c|c|c|}
\hline Orthographic & Morphological & Identity & Fragment \\
\hline \multicolumn{4}{|c|}{ Transparent.C } \\
\hline army & arms & $\operatorname{arm}$ & ar_ \\
\hline beetle & beets & beet & $b_{-}-t$ \\
\hline belly & bells & bell & b__l \\
\hline blanket & blanked & blank & b__nk \\
\hline hammer & hams & ham & ha_ \\
\hline harmony & harmed & harm & $\mathrm{h}_{-} \_\mathrm{m}$ \\
\hline listen & listed & list & $1-\_t$ \\
\hline message & messy & mess & m_s_ \\
\hline needle & needed & need & ne -- \\
\hline pillow & pills & pill & pi_-_ \\
\hline pinch & pinned & pin & pi_ \\
\hline plant & planner & plan & $p_{-}-n$ \\
\hline puppet & puppy & pup & p_p \\
\hline rocket & rocky & rock & $\mathrm{r}_{-}{ }_{-} \mathrm{k}$ \\
\hline shuttle & shutting & shut & $\mathrm{sh}_{--}$ \\
\hline start & starry & star & st_-_ \\
\hline ticket & ticked & tick & $\mathrm{ti}_{-}-$ \\
\hline turnip & turned & turn & $\mathrm{t} \_$- $\mathrm{n}$ \\
\hline warn & wars & war & w_r \\
\hline winter & winning & win & wi_ \\
\hline
\end{tabular}


APPENDIX (Continued)

\begin{tabular}{|c|c|c|c|}
\hline Orthographic & Morphological & Identity & Fragment \\
\hline \multicolumn{4}{|c|}{ Opaque } \\
\hline band & bent & bend & $b_{-} d \mathrm{~d}$ \\
\hline bet & bit & bite & $\mathrm{bi}_{-}-$ \\
\hline brick & broke & break & bre_-_ \\
\hline cheese & chosen & choose & cho__e \\
\hline cone & came & come & $\mathrm{CO}_{--}$ \\
\hline $\operatorname{dog}$ & dug & dig & $\mathrm{di}_{-}$ \\
\hline glow & grew & grow & g_o_* \\
\hline heart & heard & hear & $h_{-}-\mathrm{r}$ \\
\hline maze & made & make & m_k_ \\
\hline riddle & ridden & ride & $\mathrm{r}_{-} \mathrm{e}^{\mathrm{e}}$ \\
\hline self & sold & sell & $s_{-} \_1$ \\
\hline shark & shook & shake & sh__e \\
\hline sheep & slept & sleep & sl_e_ \\
\hline shop & shot & shoot & $\mathrm{sh}_{-} \_\mathrm{t}$ \\
\hline silk & sank & $\operatorname{sink}$ & si_-_ \\
\hline sip & sat & sit & si_ \\
\hline skin & spun & spin & spi_ \\
\hline steam & stole & steal & st__1 \\
\hline tall & told & tell & te_- \\
\hline week & wept & weep & $\mathrm{w}_{-} \_\mathrm{p}$ \\
\hline \multicolumn{4}{|c|}{ Transparent.P } \\
\hline filled & filmed & film & $\mathrm{f}_{--} \mathrm{m}$ \\
\hline pans & pens & pen & $\mathrm{pe}_{-}$ \\
\hline rusting & rushing & rush & $r_{--} h$ \\
\hline counts & courts & court & $c_{-} r t$ \\
\hline things & thinks & think & $\mathrm{t}_{-} \mathrm{i}_{-} \mathrm{k}$ \\
\hline tripped & trapped & trap & $\mathrm{t}_{-} \mathrm{a}_{-}$ \\
\hline masking & marking & mark & $\mathrm{m}_{-} \mathrm{r}_{-}$ \\
\hline lending & landing & land & $1 a_{--}$ \\
\hline hardly & handy & hand & $\mathrm{h}_{-} \mathrm{n}_{-}$ \\
\hline washed & wished & wish & wi \\
\hline decks & ducks & duck & $\mathrm{du}_{--}$ \\
\hline tents & tests & test & $\mathrm{t}_{-} \mathrm{s}_{-}$ \\
\hline claps & claws & claw & $c_{-}-w$ \\
\hline blocker & blacker & black & $\mathrm{b}_{-} \mathrm{ac}$ \\
\hline whiter & writer & write & wri \\
\hline beans & beams & beam & $\mathrm{b}_{--} \mathrm{m}$ \\
\hline scared & scored & score & $\mathrm{s}_{-} \mathrm{O} \mathrm{r}_{-}$ \\
\hline parked & parted & part & $\mathrm{p}_{--\mathrm{t}}$ \\
\hline speaking & sneaking & sneak & $\mathrm{s} \mathrm{n}{ }_{--} \mathrm{k}$ \\
\hline sweater & sweeter & sweet & $\mathrm{s}_{-} \mathrm{et}$ \\
\hline
\end{tabular}

*Ambiguous fragment, not scored.

(Manuscript received February 21, 2001;

revision accepted for publication September 7, 2001.) 